\title{
2-Methoxycinnamaldehyde inhibits the TNF- $\alpha$-induced proliferation and migration of human aortic smooth muscle cells
}

\author{
YOUNG-HEE JIN and SOO-A KIM \\ Department of Biochemistry, Dongguk University College of Oriental Medicine, Gyeongju 780-714, Republic of Korea
}

Received March 23, 2016; Accepted November 24, 2016

DOI: $10.3892 /$ ijmm.2016.2818

\begin{abstract}
The abnormal proliferation and migration of vascular smooth muscle cells (VSMCs) is a crucial event in the development of atherosclerosis, and tumor necrosis factor- $\alpha$ (TNF- $\alpha)$ is actively involved in this process by enhancing the proliferation and migration of VSMCs. 2-Methoxycinnamaldehyde (MCA) is a natural compound of Cinnamomum cassia. Although 2-hydroxycinnamaldehyde (HCA), another compound from Cinnamomum cassia, has been widely studied with regard to its antitumor activity, MCA has not attracted researchers' interest due to its mild toxic effects on cancer cells and its mechanisms of action remain unknown. In this study, we examined the effects of MCA on the TNF- $\alpha$-induced proliferation and migration of human aortic smooth muscle cells (HASMCs). As shown by our results, MCA inhibited TNF- $\alpha$-induced cell proliferation by reducing the levels of cyclin D1, cyclin D3, CDK4 and CDK6, and increasing the levels of the cyclindependent kinase inhibitors, p21 and p27, without resulting in cellular cytotoxicity. Furthermore, MCA decreased the level of secreted matrix metalloproteinase (MMP)-9 by inhibiting MMP-9 transcription. Unexpectedly, MCA did not affect the TNF- $\alpha$-induced levels of mitogen-activated protein kinases (MAPKs). However, by showing that MCA potently inhibited the degradation of $\mathrm{I} \kappa \mathrm{B} \alpha$ and the subsequent nuclear translocation of nuclear factor- $\kappa \mathrm{B}(\mathrm{NF}-\kappa \mathrm{B})$, we demonstrated that MCA exerts its effects through the NF- $\kappa \mathrm{B}$ signaling pathway. MCA also effectively inhibited platelet-derived growth factor (PDGF)-induced HASMC migration. Taken together, these observations suggest that MCA has the potential for use as an anti-atherosclerotic agent.
\end{abstract}

Correspondence to: Dr Soo-A Kim, Department of Biochemistry, Dongguk University College of Oriental Medicine, 707 Seokjang-dong, Gyeongju-si, Gyeongsangbuk-do 780-714, Republic of Korea E-mail:ksooa@dongguk.ac.kr

Key words: cinnamaldehyde, 2-methoxycinnamaldehyde, human aortic smooth muscle cell, atherosclerosis, tumor necrosis factor- $\alpha$, matrix metalloproteinase-9

\section{Introduction}

The abnormal proliferation and migration of vascular smooth muscle cells (VSMCs) are major events in the development and progression of atherosclerosis. During the early stages of atherosclerosis, VSMCs migrate from the tunica media into the tunica intima of the arterial wall, and this, along with proliferation, cause intimal thickening and narrowing of the arterial space (1).

Atherogenic lesions are characterized by the accumulation of inflammatory cells and released cytokines (2). Tumor necrosis factor- $\alpha$ (TNF- $\alpha)$ is a major inflammatory cytokine that plays an important role in the initiation and development of atherosclerosis (3). TNF- $\alpha$ is secreted by activated macrophages in atherosclerotic lesions and by VSMCs in the neointima following balloon injury; this cytokine induces the proliferation and migration of VSMCs (4-6). For VSMC migration to occur, the proteolytic degradation or remodeling of the extracellular matrix (ECM) is required. Matrix metalloproteinases (MMPs) are a family of endopeptidases that degrade ECM components, including type IV collagen, laminin and elastin $(7,8)$. Among the MMPs, MMP-9 plays a critical role in VSMC migration and neointima formation, and TNF- $\alpha$ is known to induce VSMC migration via the induction of MMP-9 expression $(9,10)$. As previously demonstrated in an animal model of restenosis, MMP-9-deficient mice exhibit reduced neointima formation due to a defect in VSMC migration, suggesting an important role for MMP-9 in the progression of atherosclerosis (11). TNF- $\alpha$ also induces the expression of cellular adhesion molecules, such as intercellular adhesion molecule-1 (ICAM-1) and vascular cell adhesion molecule-1 (VCAM-1), and recruits monocytes to injury sites, thereby enhancing the interaction between VSMCs and monocytes at inflammatory sites. This process also plays an important role in the development and progression of atherosclerosis (12). Therefore, the inhibition of TNF- $\alpha$-mediated VSMC proliferation and migration is considered an important therapeutic strategy for atherosclerosis.

Cinnamon is a widely used food spice that is obtained from the inner bark of Cinnamomum cassia. Cinnamaldehyde, an active component of cinnamon, exhibits various biological functions, such as anti-bacterial, anti-fungal, anti-inflammatory and antitumor activities (13-16). Specifically, the natural derivative, 2-hydroxycinnamaldehyde (HCA), and the synthetic derivative, 2-benzoyloxycinnamaldehyde (BCA), have been shown to effectively induce cell cycle arrest and the subsequent apoptosis of various human cancer cells, including those 
from breast, colon, leukemia, lung and oral cancers (16-19). Recently, we demonstrated that HCA induced the activation of the cell death pathway in a p53-independent manner and that autophagy was actively involved in the HCA-induced apoptosis of oral cancer cells (20). To date, the majority of studies evaluating cinnamaldehyde have focused on its antitumor activity. However, Liao et al demonstrated that cinnamaldehyde inhibited the adhesion of TNF- $\alpha$-induced monocytes to endothelial cells by suppressing the expression of the cell adhesion molecules, VCAM-1 and ICMA-1 (21). Furthermore, we recently demonstrated that BCA inhibited LPS-induced inducible nitric oxide (NO) synthase (iNOS) expression and subsequent NO production in vitro and in vivo (15). These data demonstrate the anti-inflammatory effects of cinnamaldehyde and suggest that cinnamaldehyde and its derivatives may be possible candidates for use in the treatment of inflammation-related diseases.

In the present study, we evaluated 2-methoxycinnamaldehyde (MCA), a natural cinnamaldehyde derivative, to determine whether it would be useful as an anti-atherosclerotic agent. Specifically, we evaluated the effects of MCA on the proliferation and migration of human aortic smooth muscle cells (HASMCs) that were exposed to TNF- $\alpha$. The molecular mechanisms of action of MCA as an anti-atherosclerotic agent were also assessed. To the best of our knowledge, our data provide initial evidence that MCA is a novel candidate for the treatment of atherosclerosis.

\section{Materials and methods}

Materials. The HASMCs and smooth muscle cell medium (SMCM) were purchased from ScienCell (Carlsbad, CA, USA). Recombinant human TNF- $\alpha$ was purchased from R\&D Systems (Minneapolis, MN, USA). The antibodies against cyclin D1 (\#2926), cyclin D3 (\#2936), cyclin-dependent kinase (CDK)4 (\#2906), CDK6 (\#3136), p15 (\#4822), p21 (\#2946), p27 (\#2552), p65 (\#4764), phosphorylated (p-)p65 (\#3033), IкB $\alpha$ (\#4814), c-Jun N-terminal kinase (JNK; \#9258), p-JNK (\#4668), p38 (\#9212), p-p38 (\#9211), extracellular signal-regulated kinase (ERK; \#4695) and p-ERK (\#4370) were obtained from Cell Signaling Technology (Danvers, MA, USA) and the antibodies against TATA-binding protein (TBP; ab818) were purchased from Abcam (Cambridge, MA, USA). Recombinant human platelet-derived growth factor (PDGF) and antibodies against $\beta$-actin (A1978) were purchased from Sigma-Aldrich (St. Louis, MO, USA). HCA and MCA were purchased from Santa Cruz Biotechnology, Inc. (Santa Cruz, CA, USA). Unless otherwise mentioned, all other chemicals were purchased from Sigma-Aldrich.

Cell culture and treatment. The HASMCs were maintained at $37^{\circ} \mathrm{C}$ under $5 \% \mathrm{CO}_{2}$ in SMCM supplemented with the reagents provided with the medium. The cells were treated with various concentrations $(1-50 \mu \mathrm{M})$ of MCA or HCA (dissolved in $0.1 \% \mathrm{DMSO}$ ) for the indicated periods of time.

Cell proliferation and cytotoxicity assays. The HASMCs were seeded on 12-well plates at a density of $1.5 \times 10^{5}$ cells $/ \mathrm{ml}$. The cells were cultured overnight and treated with various concentrations of MCA or HCA for $24 \mathrm{~h}$. Cell proliferation was evaluated by MTT assay according to a previously described method (22).
Table I. Primers used for semi-quantitative RT-PCR.

\begin{tabular}{lll}
\hline Gene & \multicolumn{1}{c}{$\begin{array}{c}\text { Primer sequences } \\
\left(5^{\prime} \rightarrow 3^{\prime}\right)\end{array}$} & $\begin{array}{c}\text { Size } \\
(\mathrm{bp})\end{array}$ \\
\hline MMP-9 & $\begin{array}{l}\text { F: GGATGGGAAGTACTGGCGATTCT } \\
\text { R: CACTTGGTCCACCTGGTTCAAC }\end{array}$ & 478 \\
& R: & \\
MMP-2 & F: CTTCCAAGTCTGGAGCGATGT & 209 \\
& R: TCTCCCAAGGTCCATAGCTCA & \\
TIMP1 & F: GCTGACATCCGGTTCGTCTAC & 272 \\
& R: CAAGCAATGAGTGCCACTCTG & \\
GAPDH & F: CCAAGGTCATCCATGACAACTTTG & 464 \\
& R: GTCATACCAGGAAATGAGCTTGACA & \\
\hline
\end{tabular}

MMP, matrix metalloproteinase; TIMP, tissue inhibitor of metalloproteinases; GAPDH, glyceraldehyde 3-phosphate dehydrogenase.

Briefly, each well was washed twice with PBS, and $0.5 \mathrm{ml}$ of cell culture medium and $50 \mu 1$ of 3-(4,5-dimethylthiazol-2-yl)2,5-diphenyltetrazolium bromide solution ( $5 \mathrm{mg} / \mathrm{ml}$ in PBS) were added. After $3 \mathrm{~h}$ of incubation, the medium was removed and $250 \mu \mathrm{l}$ of acid-isopropanol $(0.04 \mathrm{~mol} / 1 \mathrm{HCl}$ in isopropanol) were added. The absorbance was measured at $570 \mathrm{~nm}$ using a Microplate reader (iMarkTM; Bio-Rad, Hercules, CA, USA).

For the cell cytotoxicity assay, the cells were treated with various concentrations of MCA or HCA for $24 \mathrm{~h}$. Cell toxicity was evaluated by measuring the lactate dehydrogenase (LDH) activity using the CytoTox $96^{\circledR}$ non-radioactive assay kit (Promega, Madison, WI, USA) in accordance with the manufacturer's instructions. In brief, the supernatant of the cell media was transferred to a 96-well plate. An equal volume of CytoTox $96^{\circledR}$ reagent was then added and incubated for $30 \mathrm{~min}$ at room temperature. After adding stop solution, the absorbance was measured at $490 \mathrm{~nm}$ using a Microplate reader (iMarkTM; Bio-Rad).

Western blot analysis. The HASMCs were exposed to TNF- $\alpha$ (10 ng/ml) alone or together with MCA for $24 \mathrm{~h}$. The cells were washed with phosphate-buffered saline (PBS) and lysed in RIPA buffer (PBS supplemented with 1\% NP-40, $0.5 \%$ sodium deoxycholate, $1 \mathrm{mM}$ PMSF, $1 \mu \mathrm{g} / \mathrm{ml}$ aprotinin, and $1 \mathrm{mM}$ sodium orthovanadate). The cell lysates were then incubated at $4^{\circ} \mathrm{C}$ for $30 \mathrm{~min}$, followed by centrifugation at $10,000 \mathrm{x}$ g for $10 \mathrm{~min}$. Alternatively, the cytoplasmic and nuclear fractions were obtained using a subcellular fractionation method that has been described previously (23). The protein samples were resolved by sodium dodecyl sulfate-polyacrylamide gel electrophoresis (SDS-PAGE) and then transferred onto PVDF membranes. The blots were blocked and then incubated with primary antibodies. The immunoreactive bands were detected using the Immobilon ${ }^{\mathrm{TM}}$ Western chemiluminescent HRP substrate (Millipore, Billerica, MA, USA).

Semi-quantitative RT-PCR. The cells were exposed to TNF- $\alpha$ alone or together with various concentrations of MCA for $24 \mathrm{~h}$. Total RNA was isolated using TRIzol ${ }^{\circledR}$ reagent (Invitrogen, Carlsbad, CA, USA), and semi-quantitative RT-PCR was 


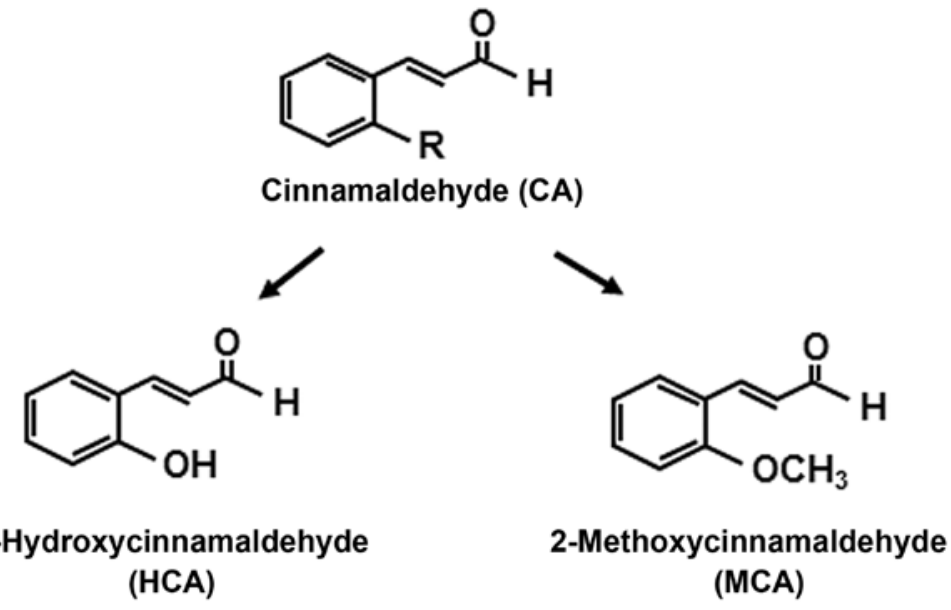

Figure 1. Chemical structure of 2-hydroxycinnamaldehyde (HCA) and 2-methoxycinnamaldehyde (MCA).

conducted using the One-Step RT-PCR PreMix kit (Intron Biotechnology, Seongnam, Korea) according to the manufacturer's instructions. The specific primers used for RT-PCR are shown in Table I. RT-PCR was performed under the following conditions: 1 cycle of $30 \mathrm{~min}$ at $45^{\circ} \mathrm{C}, 1$ cycle of $5 \mathrm{~min}$ at $94^{\circ} \mathrm{C}$, and 25 to 30 cycles of $30 \mathrm{sec}$ at $94^{\circ} \mathrm{C}, 30 \mathrm{sec}$ at $55^{\circ} \mathrm{C}$, and $40 \mathrm{sec}$ at $72^{\circ} \mathrm{C}$, with a final extension at $72^{\circ} \mathrm{C}$ for $5 \mathrm{~min}$. The PCR products were electrophoresed on a $1.7 \%$ agarose gel and visualized by ethidium bromide staining.

Gelatin zymography. The cell culture supernatants were resuspended in sample buffer (60 mM Tris-Cl, pH 6.8, $15 \%$ glycerol, $2 \%$ SDS and $0.001 \%$ bromophenol blue) and loaded, without boiling, onto a $0.1 \%$ gelatin gel containing $10 \%$ acrylamide. Following electrophoresis, the gels were washed twice with $0.25 \%$ Triton X-100 solution for $30 \mathrm{~min} /$ wash and then incubated in incubation buffer (50 mM Tris-Cl, pH 7.6, $5 \mathrm{mM} \mathrm{CaCl}_{2}$, $20 \mathrm{mM} \mathrm{NaCl}$ ) at $37^{\circ} \mathrm{C}$ for $18-24 \mathrm{~h}$ to allow for proteolysis of the gelatin. The gels were stained with Coomassie Brilliant Blue R. Proteolysis can be detected as a white zone in a dark blue field.

Luciferase reporter gene assay. A $0.71 \mathrm{~kb}$ segment at the 5'-flanking region of the human MMP-9 gene, corresponding to GenBank ${ }^{\circledR}$ accession number D10051 was amplified by PCR using genomic DNA from 293 cells (American Type Culture Collection, Manassas, VA, USA) as a template. The luciferase reporter vector for the MMP-9 promoter was created by inserting the MMP-9 promoter DNA fragment into the 5' SacI and 3' HindIII sites of the pGL3-Basic vector. The constructs were confirmed by DNA sequencing. To assess the effects of MCA on MMP-9 promoter activity, the cells were co-transfected with pGL3-MMP-9-Luc and pCH110 using the Neon Transfection system (Invitrogen) according to the manufacturer's instructions. After $30 \mathrm{~h}$, the cells were exposed to TNF- $\alpha$ and/or various concentrations of MCA for $24 \mathrm{~h}$. The cells were then lysed and luciferase activity was measured using the Luciferase assay system (Promega). The luciferase activity was normalized to the $\beta$-galactosidase activity.

Immunofluorescence microscopy. The HASMCs were seeded at a density of $1.5 \times 10^{5}$ cells $/ \mathrm{ml}$. The cells were cultured overnight and exposed to TNF- $\alpha$ and/or MCA for $3 \mathrm{~h}$. The cells were washed twice with PBS and fixed with $4 \%$ paraformaldehyde for $10 \mathrm{~min}$. After being washed twice with PBS, the cells were incubated with methanol for $2 \mathrm{~min}$. The immunostaining was performed as previously described (24). The fluorescence analysis was performed by conventional fluorescence microscopy (Axio Observer D1; Carl Zeiss, Oberkochen, Germany).

Cell migration assay. Cell migration assay was performed using the Transwell ${ }^{\circledR}$ system (Corning Inc., Corning, NY, USA). Briefly, the cells were seeded at a density of $3 \times 10^{4}$ cells $/ 100 \mu \mathrm{l}$ on a $0.1 \%$ gelatin-coated upper chamber. A $500 \mu \mathrm{l}$ aliquot of serumfree SMCM with hPDGF (10 ng/ml) and/or MCA was added to the lower compartment of the invasion chamber. Following $24 \mathrm{~h}$ of incubation, the filter insert within the upper chamber was removed. The cells on the upper side of the filter were removed using cotton swabs, and the cells that had migrated to the underside of the filter were stained with hematoxylin and eosin (H\&E). The migrated cells were observed under a light microscope (Olympus CKX41; Olympus, Tokyo, Japan).

Statistical analysis. All experiments were performed at least 3 times and the data are expressed as the means \pm SD. ANOVA and the Student's t-test were applied to determine the statistical significance. $\mathrm{P}$-values $<0.01$ were considered to indicate statistically significant differences.

\section{Results}

Effect of MCA on HASMC proliferation and cytotoxicity. In an effort to find possible anti-atherosclerotic agents, we first evaluated the effects of MCA and HCA, natural derivatives of cinnamaldehyde, on HASMC proliferation (25). Instead of a hydrogen, HCA has a hydroxy group and MCA has a methoxy group at the 2 ' site of cinnamaldehyde (Fig. 1). We, as well as others have demonstrated that HCA markedly inhibits the proliferation and induces the apoptosis of various human cancer cells $(16,18-20)$. Consistent with these studies, in this study, HCA significantly decreased cell proliferation in a dosedependent manner. Treatment with $50 \mu \mathrm{M}$ HCA reduced cell proliferation by $62.7 \%$ compared with the untreated control cells (Fig. 2A). Furthermore, HCA markedly increased cytotoxicity in a dose-dependent manner at a concentration of up to 

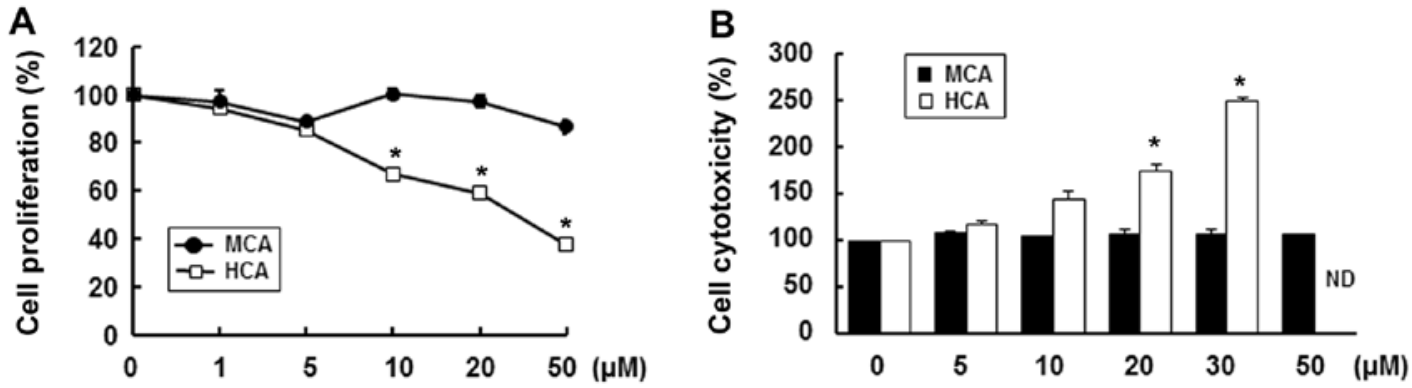

Figure 2. Effects of 2-hydroxycinnamaldehyde (HCA) and 2-methoxycinnamaldehyde (MCA) on cell proliferation and cytotoxicity. The human aortic smooth muscle cells (HASMCs) were treated with various concentrations of HCA or MCA for $24 \mathrm{~h}$. (A) Cell proliferation levels were assessed by MTT assay. ${ }^{*} \mathrm{P}<0.01$ compared with untreated control cells. (B) Cell cytotoxicity was measured by LDH assay. The data are expressed as the means \pm SD of 3 individual experiments. ${ }^{*} \mathrm{P}<0.01$ compared with untreated control cells.
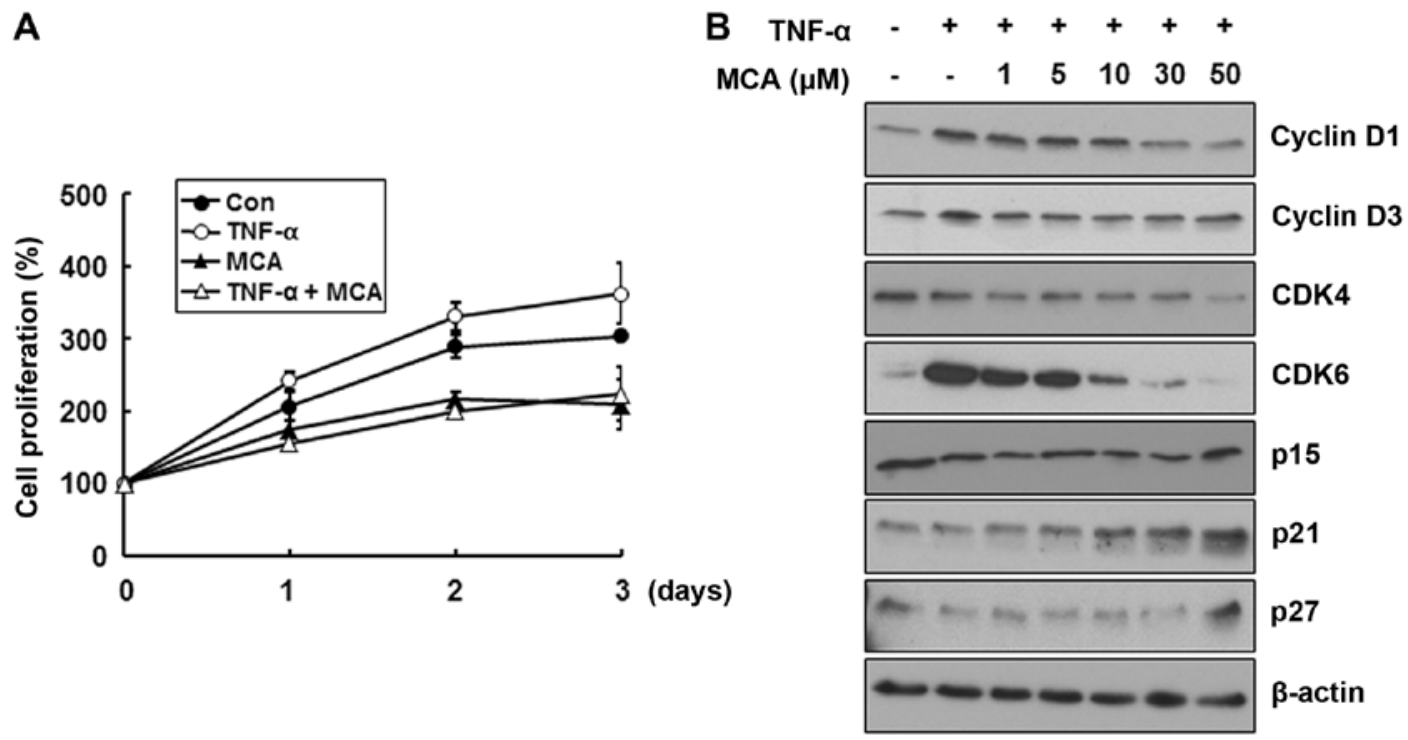

Figure 3. 2-Methoxycinnamaldehyde (MCA) suppresses tumor necrosis factor- $\alpha$ (TNF- $\alpha$ )-induced human aortic smooth muscle cell (HASMC) proliferation. (A) The HASMCs were exposed to $10 \mathrm{ng}$ of TNF- $\alpha$ and/or $50 \mu \mathrm{M}$ MCA for the indicated periods of time. Cell proliferation levels were assessed by MTT assay. The data are expressed as the means \pm SD of 3 independent experiments. (B) The cells were exposed to TNF- $\alpha$ alone or together with various concentrations of MCA for $24 \mathrm{~h}$. The total cell lysates were prepared, and the expression levels of cyclin D1, cyclin D3, CDK4, CDK6, p15, p21 and p27 were detected by western blot analysis.

$30 \mu \mathrm{M}$ (Fig. 2B). We could not obtain reasonable cytotoxicity data for concentrations $>50 \mu \mathrm{M}$ as HCA was highly toxic. On the other hand, MCA only slightly decreased cell proliferation, by $13.3 \%$, at a concentration of $50 \mu \mathrm{M}$ and did not result in any cytotoxicity up to a concentration of $50 \mu \mathrm{M}$ (Fig. 2B). Therefore, we used MCA for the subsequent experiments.

$M C A$ inhibits TNF- $\alpha$-induced HASMC proliferation. We then assessed the effects of MCA on TNF- $\alpha$-induced cell proliferation. The HASMCs were exposed to $10 \mathrm{ng} / \mathrm{ml} \mathrm{TNF}-\alpha$ alone or together with $50 \mu \mathrm{M}$ MCA for the indicated periods of time, and cell proliferation was monitored by MTT assay. TNF- $\alpha$ increased cell proliferation by approximately $19.2 \%$ at day 3 compared with the untreated control cells, while MCA decreased cell proliferation by approximately $31.1 \%$ (Fig. 3A). More importantly, MCA completely abolished the TNF- $\alpha$ induced increase in HASMC proliferation (Fig. 3A). To confirm the inhibitory effects of MCA on TNF- $\alpha$-induced cell proliferation, we then examined the expression levels of cell cycle regulatory proteins. The cells were exposed to TNF- $\alpha$ alone or with a combination of various concentrations of MCA for $24 \mathrm{~h}$. TNF- $\alpha$ increased the levels of cyclin D1 and cyclin D3 and markedly increased the levels of CDK6 (Fig. 3B). Of note, MCA attenuated the TNF- $\alpha$-induced increase in the levels of cyclin D1, cyclin D3 and CDK6 in a dose-dependent manner compared with the control levels of these proteins. Additionally, the levels of the CDK inhibitor (CDKI) proteins, p21 and p27, were increased by MCA. These results suggest that MCA effectively suppresses TNF- $\alpha$-induced cell proliferation through the regulation of cell cycle regulatory proteins.

MCA inhibits the TNF- $\alpha$-induced increase in MMP-9 expression. MMP-9 plays an important role in VSMC proliferation and migration, and the expression of MMP-9 can be induced by TNF- $\alpha(9,10)$. Thus, to assess whether MCA affects TNF- $\alpha-$ induced MMP-9 expression, a gelatin zymography assay was performed. While no MMP-9 activity was detected in the medium from the untreated control cells, exposure to TNF- $\alpha$ markedly enhanced the secretion of MMP-9, and MCA significantly inhibited the secretion of MMP-9 in a dose-dependent manner (Fig. 4A). Unlike MMP-9, MMP-2 exhibited high proteolytic activity in the medium from the untreated control 

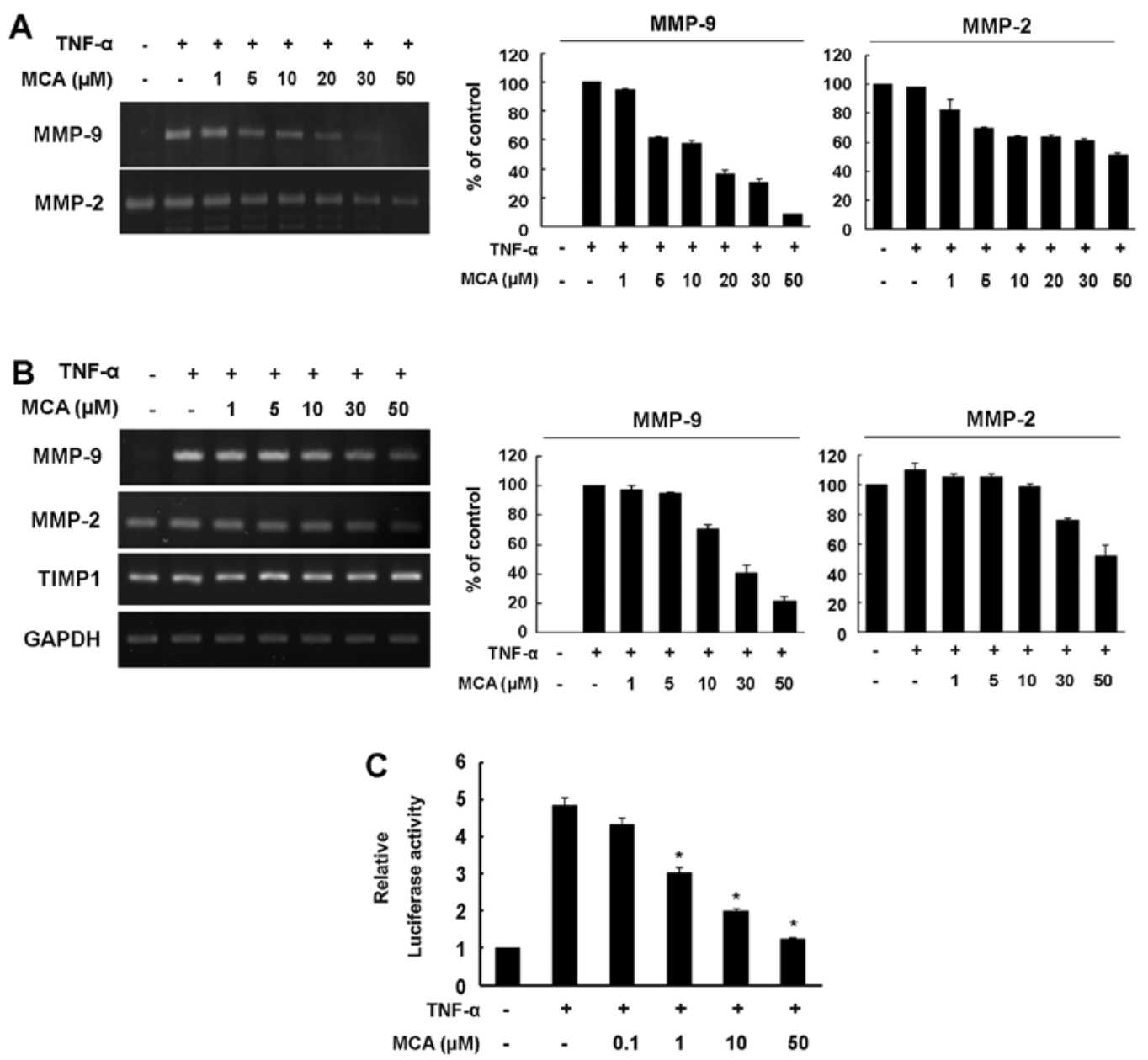

Figure 4. 2-Methoxycinnamaldehyde (MCA) inhibits the tumor necrosis factor- $\alpha$ (TNF- $\alpha$ )-induced increase in matrix metalloproteinase-9 (MMP-9) expression in human aortic smooth muscle cells (HASMCs). (A) The cells were exposed to TNF- $\alpha$ alone or together with various concentrations of MCA for 24 h. Gelatin zymography analyses for MMP-9 and MMP-2 were performed using the cell culture supernatants. (B) The cells were exposed to TNF- $\alpha$ alone or together with the indicated concentrations of MCA for $24 \mathrm{~h}$. Total RNA was isolated, and semi-quantitative RT-PCR was performed using the specific primers listed in Table I. Glyceraldehyde 3-phosphate dehydrogenase (GAPDH) was used as an internal control. (C) The cells were transfected with the pGL3-MMP-9-Luc reporter vector. After $30 \mathrm{~h}$, the cells were exposed to TNF- $\alpha$ alone or together with the indicated concentrations of MCA for $24 \mathrm{~h}$. The total cell extracts were subjected to the luciferase assay. Luciferase activities were normalized by co-transfection with a $\beta$-galactosidase-expressing vector, pCH110. The data are expressed as the means \pm SD of 3 individual experiments. ${ }^{*} \mathrm{P}<0.01$ compared with TNF- $\alpha$-treated control cells.

cells. Although TNF- $\alpha$ did not affect the level of MMP-2, MCA slightly reduced the level of MMP-2. Compared with the TNF- $\alpha$-exposed controls, MCA inhibited MMP-9 and MMP-2 secretion by approximately 91.5 and $48.8 \%$, respectively (Fig. 4A).

We then examined whether the MCA-dependent decrease in MMP-9 secretion is caused by the transcriptional regulation of the MMP-9 gene. The cells were exposed to TNF- $\alpha$ alone or together with various concentrations of MCA for $24 \mathrm{~h}$. Total RNA was then isolated, and semi-quantitative RT-PCR was performed. Consistent with the results from zymography assay, TNF- $\alpha$ markedly increased the mRNA level of MMP-9, and the TNF- $\alpha$-induced increase in the MMP-9 mRNA levels was attenuated by MCA in a dose-dependent manner, with a $78.7 \%$ inhibition observed in the cells treated with MCA. The constitutive mRNA expression of MMP-2 was also downregulated, exhibiting a $48 \%$ inhibition in the MCA-treated cells. However, MCA did not affect the transcription of tissue inhibitor of metalloproteinases (TIMP)1 (Fig. 4B).

To further confirm the transcriptional regulation of MMP-9 by MCA, a luciferase reporter gene assay was performed. The cells were transfected with the pGL3-MMP-9-Luc reporter vector and then exposed to TNF- $\alpha$ alone or together with various concentrations of MCA. TNF- $\alpha$ enhanced MMP-9 promoter activity up to 5-fold compared with the untreated controls (Fig. 4C). However, when the cells were treated with MCA in the presence of TNF- $\alpha$, MMP-9 promoter activity was reduced in a dose-dependent manner, suggesting that MCA inhibits TNF- $\alpha$-induced MMP-9 transcriptional activity.

$M C A$ inhibits $T N F-\alpha$-induced $N F-\kappa B$ nuclear translocation. To further understand the molecular mechanisms through which MCA alters MMP-9 expression, the effects of MCA on mitogen-activated protein kinase (MAPK) signaling pathways were examined. Although TNF- $\alpha$ induced the activation of JNK and ERK, MCA did not affect the JNK, p38 and ERK signaling pathways, suggesting that MCA functions through another signaling pathway (Fig. 5).

As MCA did not exert any significant effects on the TNF- $\alpha$ induced activation of MAPK signaling pathways, we examined the activity of the transcription factor, $N F-\kappa B$, a well-known effector of TNF- $\alpha$. As the nuclear translocation of $N F-\kappa B$ is 


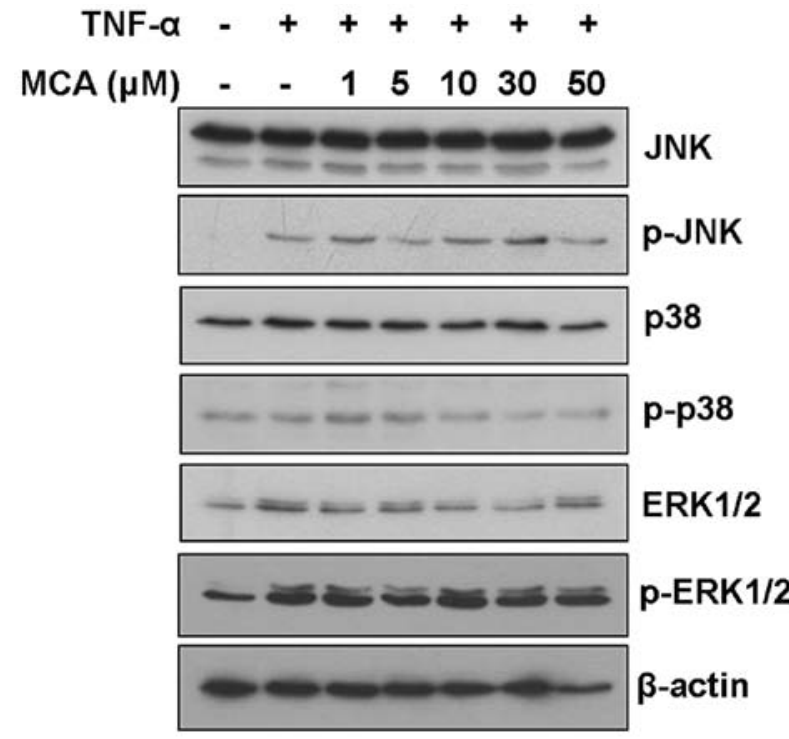

Figure 5. Effects of 2-methoxycinnamaldehyde (MCA) on tumor necrosis factor- $\alpha($ TNF- $\alpha)$-induced MAPK activation. The human aortic smooth muscle cells (HASMCs) were exposed to TNF- $\alpha$ alone or together with various concentrations of MCA for $24 \mathrm{~h}$. The total cell lysates were prepared, and the levels of JNK, p38, ERK1/2, p-JNK, p-p38 and p-ERK1/2 were detected by western blot analysis.

an important indicator of its activation, we evaluated whether MCA affects NF- $\kappa \mathrm{B}$ subcellular translocation. For this experiment, the HASMCs were exposed to TNF- $\alpha$ and/or MCA for $24 \mathrm{~h}$. The nuclear proteins were separated from the cytosolic proteins through fractionation, and the distribution of $\mathrm{NF}-\kappa \mathrm{B}$ was evaluated. As expected, TNF- $\alpha$ markedly enhanced the nuclear localization of the NF- $\mathrm{B}$ p65 subunit. However, MCA significantly inhibited the TNF- $\alpha$-induced nuclear localization of p65. We also demonstrated that the TNF- $\alpha$-induced nuclear p65 was phosphorylated, which is required for $\mathrm{NF}-\kappa \mathrm{B}$ activation (Fig. 6A). It is well known that the nuclear translocation of p65 is caused by the degradation of $\mathrm{I} \kappa \mathrm{B} \alpha$. Thus, to confirm the effects of MCA on the activation of NF- $\kappa B$, the levels of I $\kappa \mathrm{B} \alpha$ were evaluated. Exposure to TNF- $\alpha$ decreased the level of I $\kappa \mathrm{B} \alpha$ compared with the untreated controls (Fig. 6B). However, MCA effectively inhibited the TNF- $\alpha$-induced IкB $\alpha$ degradation. The effects of MCA on $\mathrm{NF}-\kappa \mathrm{B}$ activation were also assessed by immunofluorescence staining. Under the control conditions, NF- $\kappa \mathrm{B}$ was mainly localized in the cytoplasm, and exposure to TNF- $\alpha$ induced the nuclear translocation of $\mathrm{NF}-\kappa \mathrm{B}$. However, co-treatment with MCA and TNF- $\alpha$ resulted in the cytoplasmic localization of $\mathrm{NF}-\kappa \mathrm{B}$, suggesting that $\mathrm{MCA}$ inhibits the TNF- $\alpha$-induced NF- $\kappa$ B translocation (Fig. 6C).

MCA inhibits cytokine-induced HASMC migration. Our results demonstrated that MCA effectively inhibited the TNF- $\alpha$-induced HASMC proliferation and migration by inhibiting the activation of the NF- $\kappa$ B signaling pathway. To further evaluate the potential of MCA as an anti-atherosclerotic agent, a migration assay was performed. For this experiment, HASMC migration was induced by treating the cells with PDGF. PDGF is the strongest chemoattractant that contributes to the progression of atherosclerosis by inducing the proliferation and migration of VSMCs $(2,26)$. Treatment with PDGF (10 ng/ml) markedly enhanced HASMC migration (Fig. 7). However, combined treatment with PDGF and MCA significantly inhibited the PDGF-induced cell migration, suggesting that MCA may be a potential therapeutic agent for atherosclerosis. The TNF- $\alpha$-induced cell migration was also effectively inhibited by MCA (data not shown).

\section{Discussion}

Researches evaluating the pharmacological properties of cinnamaldehyde and its derivatives have focused on its antitumor activity. Among the known natural constituents isolated from Cinnamomum cassia, HCA is the most widely studied due to its antitumor activity (16,18-20). However, MCA, another constituent of Cinnamomum cassia, has not attracted researchers' interest due to its moderate cytotoxic effects on cancer cells.

The proliferation and migration of VSMCs are critical events in the development of atherosclerotic lesions and cytokines, such as TNF- $\alpha$ and PDGF, are intimately involved in regulating these processes $(4-6,26)$. The first response upon vascular injury is increased SMC proliferation, which continues for 1 to 3 days following injury. In the second phase of lesion development, SMCs migrate from the internal lamina to the intima, usually beginning at day $3(1,2,4)$. In this study, we evaluated the antiatherosclerotic effects of MCA on HASMCs. As expected, HCA exhibited strong cytotoxicity, while MCA did not result in any cytotoxicity up to a concentration of $50 \mu \mathrm{M}$ (Fig. 2B). Even $100 \mu \mathrm{M}$ MCA did not result in any cytotoxicity (data not shown). Furthermore, MCA effectively inhibited the TNF- $\alpha$ induced HASMC proliferation, primarily by decreasing the levels of cyclin D1/CDK6 and inducing the expression of the CDKIs, p21 and p27 (Fig. 3). These results suggest that MCA may be a suitable candidate for the treatment of atherosclerosis.

MMPs play an important role in ECM degradation and remodeling. Among them, MMP-9 and MMP-2 actively contribute to the pathogenesis of atherosclerosis by facilitating the migration of smooth muscle cells into the intima $(11,27,28)$. Furthermore, experiments with knock-out mice showed that MMP-9 is critical for the development of arterial lesions due to its role in regulating VSMC migration and proliferation $(11,28,29)$. Although MMP-9 and MMP-2 have similar substrate specificities, their expression patterns are differentially regulated. MMP-2 is constitutively expressed in smooth muscle cells, and its expression is not affected by cytokines. By contrast, the basal level of MMP-9 is very low, and its expression can be induced by TNF- $\alpha(30,31)$. In this study, the effects of MCA on TNF- $\alpha$-induced MMP-9 expression were assessed, and the data demonstrated that MCA significantly inhibited TNF- $\alpha$-induced MMP-9 secretion via the suppression of MMP-9 transcription (Fig. 4). Although the effect was small, MCA also inhibited the constitutive expression of MMP-2 at the transcriptional level.

Previous studies have reported that the induction of MMP-9 expression by TNF- $\alpha$ is regulated by the ERK and JNK signaling pathways, and by the subsequent activation of $\mathrm{NF}-\kappa \mathrm{B}$ and activator protein 1 (AP-1) in VSMCs (32-34). To understand the precise molecular mechanisms of action for MCA, MAPK activity was examined. Consistent with previous studies, the levels of p-JNK and p-ERK1/2 were elevated by exposure to TNF- $\alpha$. However, treatment with MCA did not affect the levels of phosphorylated MAPKs, suggesting that MCA inhibits MMP-9 expression through a different signaling 
A

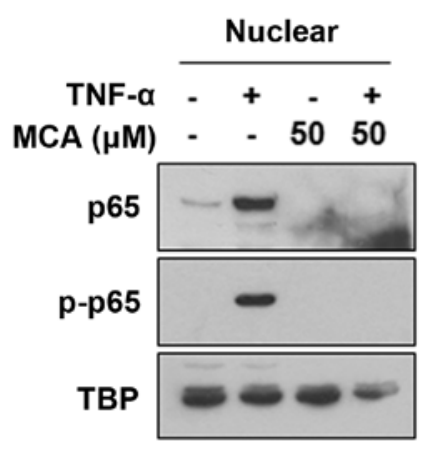

B TNF- $\alpha++\cdot+$ MCA ( $\mu \mathrm{M}) \quad-\quad 5050$
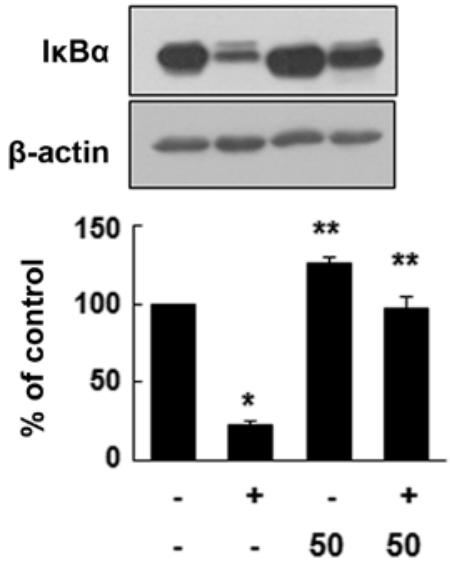

C
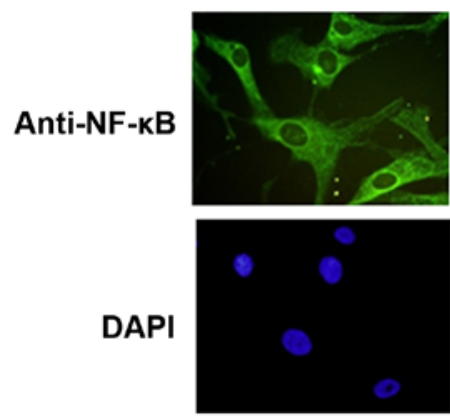

TNF- $\alpha$
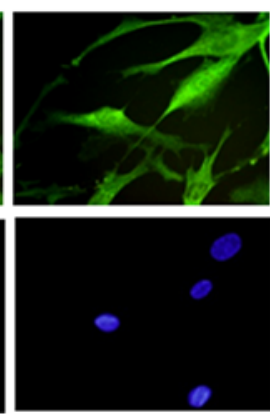

MCA
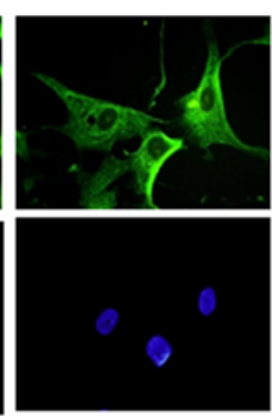

TNF- $\alpha+$ MCA
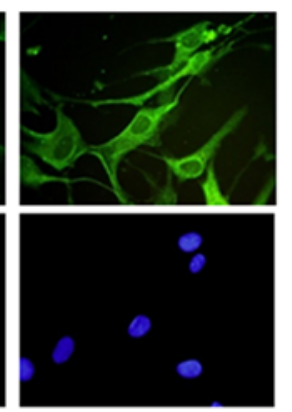

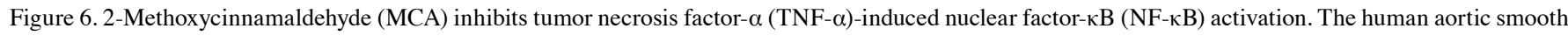
muscle cells (HASMCs) were exposed to TNF- $\alpha$ and/or MCA for $24 \mathrm{~h}$. (A) The nuclear fractions were prepared, and the levels of p65 and p-p65 were detected by western blot analysis. (B) The total cell lysates were prepared, and the levels of IкB $\alpha$ were detected by western blot analysis. The band densities were quantified by densitometry. The data are expressed as the means $\pm \mathrm{SD}$ of the 3 independent experiments. ${ }^{*} \mathrm{p}<0.01$ compared with control cells and ${ }^{* *} \mathrm{p}<0.01$ compared with TNF- $\alpha$-exposed cells. (C) The cells were exposed to TNF- $\alpha$ and/or MCA for $3 \mathrm{~h}$. The localization of NF-kB was detected by immunostaining with anti-p65 antibody and a FITC-conjugated secondary antibody. The nuclei were stained with 4',6-diamidino-2-phenylindole (DAPI).
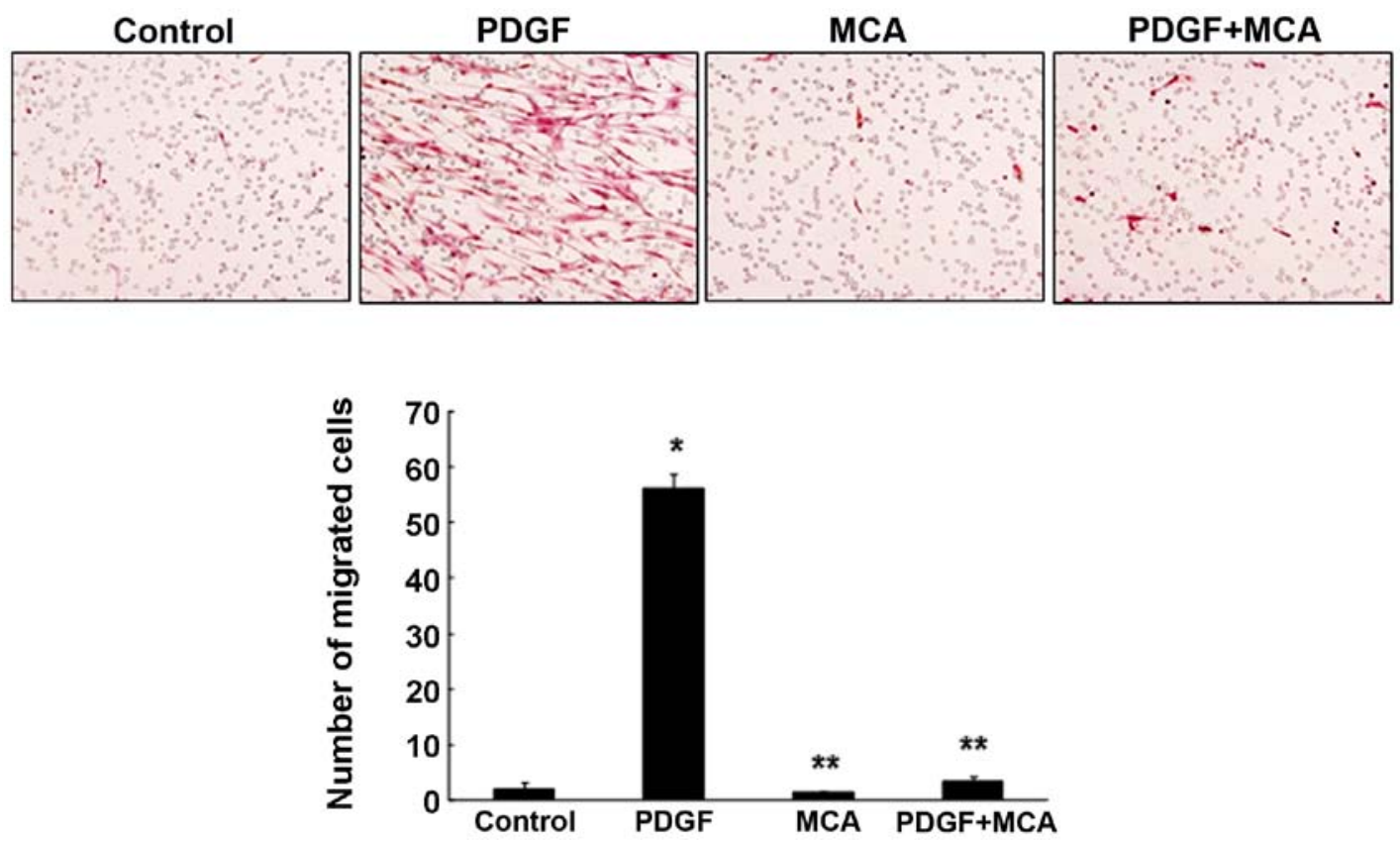

Figure 7. 2-Methoxycinnamaldehyde (MCA) inhibits platelet-derived growth factor (PDGF)-induced human aortic smooth muscle cells (HASMCs) migration The migration assay was performed by treating the HASMCs with $10 \mathrm{ng}$ of PDGF and/or $50 \mu \mathrm{M}$ MCA for $24 \mathrm{~h}$. The migrated cells were stained with H\&E and counted under a light microscope. The data are expressed as the means \pm SD of 3 independent experiments. ${ }^{*} p<0.01$ compared with control cells and ${ }^{* * *} \mathrm{p}<0.01$ compared with PDGF-treated cells. 
pathway (Fig. 5). Furthermore, our data clearly demonstrated that MCA inhibited the TNF- $\alpha$-induced increase in MMP-9 expression through the inhibition of $\mathrm{I} \kappa \mathrm{B} \alpha$ degradation and, therefore, of subsequent NF- $\kappa \mathrm{B}$ activation (Fig. 6).

PDGF is a well-known mitogen and chemoattractant for VSMCs. Similar to TNF- $\alpha$, PDGF potently stimulates VSMC proliferation and migration and plays an important role in the development of atherosclerosis $(2,26)$. To confirm the anti-atherosclerotic effects of MCA, we also examined the effect of MCA on PDGF-induced HASMC migration; the data clearly demonstrated that MCA potently inhibited, not only TNF- $\alpha-$ (data not shown), but also PDGF-induced cell migration (Fig. 7).

In this study, we demonstrated that MCA effectively inhibited TNF- $\alpha$-induced HASMC proliferation by reducing the levels of cyclin D1/CDK6 and increasing the levels of the CDKIs, p21 and p27. Furthermore, we demonstrated that MCA potently inhibited the TNF- $\alpha$-induced increase in MMP-9 expression at the transcriptional level by inhibiting the nuclear translocation of $\mathrm{NF}-\kappa \mathrm{B}$ via a MAPK-independent signaling pathway. To the best of our knowledge, this is the first study showing that MCA, a natural constituent of Cinnamomum cassia, effectively inhibits TNF- $\alpha$-induced HASMC proliferation and migration, and this study suggests that MCA may be a potential candidate for the treatment of atherosclerosis.

\section{Acknowledgements}

The present study was supported by the MRC program of MOST/KOSEF (no. R13-2005-013-01000-0).

\section{References}

1. Ross R: The pathogenesis of atherosclerosis: A perspective for the 1990s. Nature 362: 801-809, 1993.

2. Abedi $\mathrm{H}$ and Zachary I: Signalling mechanisms in the regulation of vascular cell migration. Cardiovasc Res 30: 544-556, 1995.

3. McKellar GE, McCarey DW, Sattar N and McInnes IB: Role for TNF in atherosclerosis? Lessons from autoimmune disease. Nat Rev Cardiol 6: 410-417, 2009.

4. Hansson GK: Inflammation, atherosclerosis, and coronary artery disease. N Engl J Med 352: 1685-1695, 2005.

5. Hoefer IE, van Royen N, Rectenwald JE, Bray EJ, Abouhamze Z, Moldawer LL, Voskuil M, Piek JJ, Buschmann IR and Ozaki CK: Direct evidence for tumor necrosis factor- $\alpha$ signaling in arteriogenesis. Circulation 105: 1639-1641, 2002.

6. Clausell N, de Lima VC, Molossi S, Liu P, Turley E, Gotlieb AI, Adelman AG and Rabinovitch M: Expression of tumour necrosis factor alpha and accumulation of fibronectin in coronary artery restenotic lesions retrieved by atherectomy. Br Heart J 73: 534-539, 1995.

7. Woessner JF Jr: MMPs and TIMPs - an historical perspective. Mol Biotechnol 22: 33-49, 2002.

8. Siefert SA and Sarkar R: Matrix metalloproteinases in vascular physiology and disease. Vascular 20: 210-216, 2012.

9. Li H, Liang J, Castrillon DH, DePinho RA, Olson EN and Liu ZP: FoxO4 regulates tumor necrosis factor alpha-directed smooth muscle cell migration by activating matrix metalloproteinase 9 gene transcription. Mol Cell Biol 27: 2676-2686, 2007.

10. Xiong W, MacTaggart J, Knispel R, Worth J, Persidsky Y and Baxter BT: Blocking TNF-alpha attenuates aneurysm formation in a murine model. J Immunol 183: 2741-2746, 2009.

11. Johnson C and Galis ZS: Matrix metalloproteinase-2 and -9 differentially regulate smooth muscle cell migration and cellmediated collagen organization. Arterioscler Thromb Vasc Biol 24: 54-60, 2004.

12. Huo Y and Ley K: Adhesion molecules and atherogenesis. Acta Physiol Scand 173: 35-43, 2001.

13. Kwon JA, Yu CB and Park HD: Bacteriocidal effects and inhibition of cell separation of cinnamic aldehyde on Bacillus cereus. Lett Appl Microbiol 37: 61-65, 2003.
14. Cheng SS, Liu JY, Chang EH and Chang ST: Antifungal activity of cinnamaldehyde and eugenol congeners against wood-rot fungi. Bioresour Technol 99: 5145-5149, 2008.

15. Kwon JY, Hong SH, Park SD, Ahn SG, Yoon JH, Kwon BM and Kim SA: 2'-Benzoyloxycinnamaldehyde inhibits nitric oxide production in lipopolysaccharide-stimulated RAW 264.7 cells via regulation of AP-1 pathway. Eur J Pharmacol 696: 179-186, 2012.

16. Lee CW, Hong DH, Han SB, Park SH, Kim HK, Kwon BM and Kim HM: Inhibition of human tumor growth by 2'-hydroxy- and 2'-benzoyloxycinnamaldehydes. Planta Med 65: 263-266, 1999.

17. Han DC, Lee MY, Shin KD, Jeon SB, Kim JM, Son KH, Kim HC, Kim HM and Kwon BM: 2'-benzoyloxycinnamaldehyde induces apoptosis in human carcinoma via reactive oxygen species. J Biol Chem 279: 6911-6920, 2004.

18. Lee CW, Lee SH, Lee JW, Ban JO, Lee SY, Yoo HS, Jung JK, Moon DC, Oh KW and Hong JT: 2-hydroxycinnamaldehyde inhibits SW620 colon cancer cell growth through AP-1 inactivation. J Pharmacol Sci 104: 19-28, 2007.

19. Kim SA, Sung YK, Kwon BM, Yoon JH, Lee H, Ahn SG and Hong SH: 2'-Hydroxycinnamaldehyde shows antitumor activity against oral cancer in vitro and in vivo in a rat tumor model. Anticancer Res 30: 489-494, 2010.

20. Ahn SG, Jin YH, Yoon JH and Kim SA: The anticancer mechanism of 2'-hydroxycinnamaldehyde in human head and neck cancer cells. Int J Oncol 47: 1793-1800, 2015.

21. Liao BC, Hsieh CW, Liu YC, Tzeng TT, Sun YW and Wung BS: Cinnamaldehyde inhibits the tumor necrosis factor- $\alpha$-induced expression of cell adhesion molecules in endothelial cells by suppressing NF-kappaB activation: Effects upon IkappaB and Nrf2. Toxicol Appl Pharmacol 229: 161-171, 2008.

22. Kim SA, Kim YC, Kim SW, Lee SH, Min JJ, Ahn SG and Yoon JH: Antitumor activity of novel indirubin derivatives in rat tumor model. Clin Cancer Res 13: 253-259, 2007.

23. Jin YH, Ahn SG and Kim SA: BAG3 affects the nucleocytoplasmic shuttling of HSF1 upon heat stress. Biochem Biophys Res Commun 464: 561-567, 2015.

24. Kim EJ, Park WH, Ahn SG, Yoon JH, Kim SW and Kim SA: 5'-nitro-indirubinoxime inhibits inflammatory response in TNF-alpha stimulated human umbilical vein endothelial cells. Atherosclerosis 211: 77-83, 2010

25. Ngoc TM, Nhiem NX, Khoi NM, Son DC, Hung TV and Van Kiem P: A new coumarin and cytotoxic activities of constituents from Cinnamomum cassia. Nat Prod Commun 9: 487-488, 2014.

26. Kim HJ, Cha BY, Choi B,Lim JS, Woo JT and Kim JS: Glyceollins inhibit platelet-derived growth factor-mediated human arterial smooth muscle cell proliferation and migration. Br J Nutr 107: 24-35, 2012.

27. Bendeck MP, Zempo N, Clowes AW, Galardy RE and Reidy MA: Smooth muscle cell migration and matrix metalloproteinase expression after arterial injury in the rat. Circ Res 75: 539-545, 1994.

28. Galis ZS, Johnson C, Godin D, Magid R, Shipley JM, Senior RM and Ivan E: Targeted disruption of the matrix metalloproteinase-9 gene impairs smooth muscle cell migration and geometrical arterial remodeling. Circ Res 91: 852-859, 2002.

29. Cho A and Reidy MA: Matrix metalloproteinase-9 is necessary for the regulation of smooth muscle cell replication and migration after arterial injury. Circ Res 91: 845-851, 2002.

30. Galis ZS, Muszynski M, Sukhova GK, Simon-Morrissey E, Unemori EN, Lark MW, Amento E and Libby P: Cytokinestimulated human vascular smooth muscle cells synthesize a complement of enzymes required for extracellular matrix digestion. Circ Res 75: 181-189, 1994.

31. Fabunmi RP, Baker AH, Murray EJ, Booth RF and Newby AC: Divergent regulation by growth factors and cytokines of $95 \mathrm{kDa}$ and $72 \mathrm{kDa}$ gelatinases and tissue inhibitors or metalloproteinases-1, -2 , and -3 in rabbit aortic smooth muscle cells Biochem J 315: 335-342, 1996.

32. Moon SK, Cho GO, Jung SY, Gal SW, Kwon TK, Lee YC, Madamanchi NR and Kim CH: Quercetin exerts multiple inhibitory effects on vascular smooth muscle cells: Role of ERK1/2, cell-cycle regulation, and matrix metalloproteinase-9. Biochem Biophys Res Commun 301: 1069-1078, 2003.

33. Karki R, Jeon ER and Kim DW: Nelumbo nucifera leaf extract inhibits neointimal hyperplasia through modulation of smooth muscle cell proliferation and migration. Nutrition 29: 268-275, 2013.

34. Suh SJ, Kwak CH, Chung TW, Park SJ, Cheeeei M, Park SS Seo CS, Son JK, Chang YC, Park YG, et al: Pimaric acid from Aralia cordata has an inhibitory effect on TNF- $\alpha$-induced MMP-9 production and HASMC migration via down-regulated NF- $\mathrm{B}$ and AP-1. Chem Biol Interact 199: 112-119, 2012. 